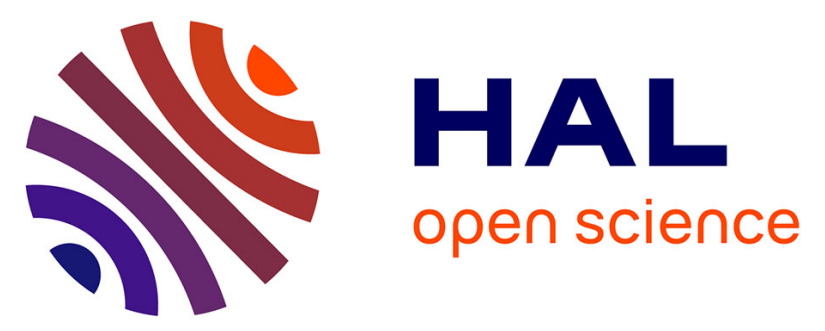

\title{
First-principles structural stability in the Strontium-Titanium-Oxygen system
}

\author{
Olivier Le Bacq, Elias Salinas, Alexander Pisch, Claude Bernard, Alain
}

Pasturel

\section{- To cite this version:}

Olivier Le Bacq, Elias Salinas, Alexander Pisch, Claude Bernard, Alain Pasturel. First-principles structural stability in the Strontium-Titanium-Oxygen system. Philosophical Magazine, 2006, 86 (15), pp.2289-2298. 10.1080/14786430500509047 . hal-00513648

\section{HAL Id: hal-00513648 \\ https://hal.science/hal-00513648}

Submitted on 1 Sep 2010

HAL is a multi-disciplinary open access archive for the deposit and dissemination of scientific research documents, whether they are published or not. The documents may come from teaching and research institutions in France or abroad, or from public or private research centers.
L'archive ouverte pluridisciplinaire HAL, est destinée au dépôt et à la diffusion de documents scientifiques de niveau recherche, publiés ou non, émanant des établissements d'enseignement et de recherche français ou étrangers, des laboratoires publics ou privés. 


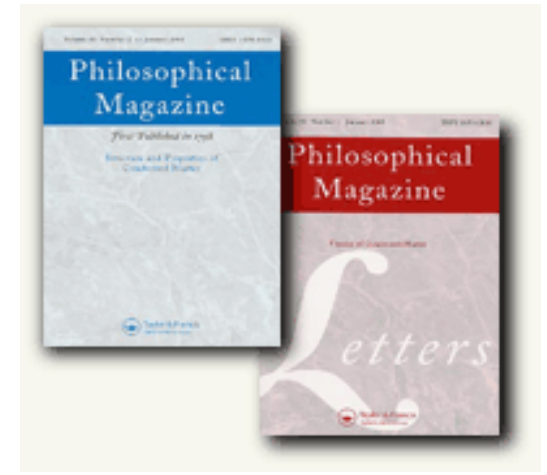

\section{First-principles structural stability in the Strontium- Titanium-Oxygen system}

\begin{tabular}{|c|c|}
\hline Journal: & Philosophical Magazine \& Philosophical Magazine Letters \\
\hline Manuscript ID: & TPHM-05-Oct-0445 \\
\hline Journal Selection: & Philosophical Magazine \\
\hline $\begin{array}{r}\text { Date Submitted by the } \\
\text { Author: }\end{array}$ & 17-Oct-2005 \\
\hline Complete List of Authors: & $\begin{array}{l}\text { Pasturel, Alain; Universite de Grenoble, Laboratoire de Physique et } \\
\text { Modelisation des Milieux Condenses } \\
\text { Le Bacq, Olivier; CNRS, Laboratoire de Thermodynamique et de } \\
\text { Physico-Chimie Metallurgiques } \\
\text { Salinas, Elias; CNRS, Laboratoire de Thermodynamique et de } \\
\text { Physico-Chimie Metallurgiques } \\
\text { PISCH, Alexander; CNRS, Laboratoire de Thermodynamique et de } \\
\text { Physico-Chimie Metallurgiques } \\
\text { Bernard, Claude; CNRS, Laboratoire de Thermodynamique et de } \\
\text { Physico-Chimie Metallurgiques }\end{array}$ \\
\hline Keywords: & first-principles calculations, titanium \\
\hline Keywords (user supplied): & \\
\hline
\end{tabular}

\section{S ScholarONE" \\ Manuscript Central}




\title{
First-principles structural stability in the Strontium-Titanium-Oxygen system
}

\author{
O. Le Bacq, E. Salinas, A. Pisch, C. Bernard
}

Laboratoire de Thermodynamique et de Physico-Chimie Métallurgiques, UMR 5614 (CNRS, INPG, UJF), Domaine Universitaire, B.P. 75, 38402 St Martin d'Hères Cedex, France

\begin{abstract}
A. Pasturel
Laboratoire de Physique et Modélisation des Milieux Condensés (LPMMC), Maison des magistères - CNRS, BP166, 38042 Grenoble Cedex09, France
\end{abstract}

\begin{abstract}
:
First principles calculations have been made to theoretically interpret the structural stability of $\mathrm{SrTiO}_{3}$ as a function of pressure or strain. We show that the orthorhombic Pbnm structure is more stable than the ideal perovskite one due to rotations of $\mathrm{TiO}_{6}$ octahedra at high pressures or deformations of $\mathrm{TiO}_{6}$ octahedra at low pressures. Such a study is extended to the structural stability of the Ruddlesden-Popper $\mathrm{Sr}_{n+1} \mathrm{Ti}_{n} \mathrm{O}_{3 n+1}$ phases for $\mathrm{n}=1,2$ and 3, in which the lattice constraints are induced by the intercalation of $\mathrm{SrO}$ layers in the perovskite structure.
\end{abstract}

Corresponding author: pasturel@grenoble.cnrs.fr 


\section{INTRODUCTION:}

Strontium titanate $\left(\mathrm{SrTiO}_{3}\right)$ is a typical perovskite dielectric with a wide range of technological applications [1,2]. Because of its special properties related to ferroelectricity [3, 4], semiconductivity [5-9], superconductivity [10-12], and catalytic activity [2], strontium titanate has been extensively studied over the years. Very recently, the high dielectric constant and electron spin polarization of $\mathrm{SrTiO}_{3}$ make it attractive for further development of tunnelling semiconductor valves and magnetic tunnel junctions for spintronics applications [13-18].

However, there are many problems to be solved on the way to maintaining such devices. More particularly, understanding the effects of temperature, pressure, strain and substrate constraint as well as the effects of nonstoichiometric chemical compositions on the phase transitions of $\mathrm{SrTiO}_{3}$ or parent compounds is a crucial issue in order to achieve desirable performance and reliability. At room pressure, $\mathrm{SrTiO}_{3}$ transforms at $110 \mathrm{~K}$ from tetragonal to cubic. Up to its melting temperature, $\mathrm{SrTiO}_{3}$ is known to remain cubic (space group $\mathrm{Pm} 3 \mathrm{~m}$ ) but in contrast, the isovalent $\mathrm{SrZrO}_{3}$ compound is orthorhombic at room temperature and undergoes a series of phase transitions as a function of temperature. Interestingly, epitaxial $\mathrm{SrTiO}_{3}$ films undergo phase transitions leading to either tetragonal or orthorhombic structures [19]. It is also known that excess strontium in $\mathrm{SrTiO}_{3}$ results in a structural planar accommodation as Ruddlesden-Popper (RP) phases of general formula $(\mathrm{SrO})\left(\mathrm{SrTiO}_{3}\right)_{\mathrm{n}}[20]$. The presence of these layers, as ordered forms of a homologous series of $(\mathrm{SrO})\left(\mathrm{SrTiO}_{3}\right)_{\mathrm{n}}$, or disordered forms of intergrown $\mathrm{RP}$ phase lamellae, were corroborated as stable phases by $\mathrm{x}$-ray diffraction and transmission electron microscopy [21-24].

Despite all the experimental efforts, little is known about the fundamental properties of $\mathrm{SrTiO}_{3}$ and $(\mathrm{SrO})\left(\mathrm{SrTiO}_{3}\right)_{\mathrm{n}}$ compounds and a comprehensive knowledge of the thermodynamic bulk properties of all these phases is still missing. More particularly, theoretical investigations of the relative structural stability of the different RP phases lead to contradictory results. Using first-principles-based calculations, Suzuki and Fujimoto [25] shows a lower exothermic formation energy for $\mathrm{Sr}_{2} \mathrm{TiO}_{4}$ than for $\mathrm{Sr}_{3} \mathrm{Ti}_{2} \mathrm{O}_{7}$, which is opposite to the result obtained by Noguera using a semiempirical Hartree-Fock method [26]. Empirical simulations based on a parameterization description of the interatomic interactions give other 


\section{METHOD :}

The density functional (DFT) calculations were performed by the Vienna ab initio simulation package (VASP) [27], making use of the projector augmented waves (PAW) technique [28]. For the exchange correlation functional, we use the generalized gradient approximation (GGA) of Perdew and Wang [29]. In the present PAW potentials, the $3 \mathrm{~d}$ and $4 \mathrm{~s}$ orbitals as well as the semicore $3 p$ orbitals are treated as valence orbitals for Ti while $5 \mathrm{~s}$ and the semicore $4 s$ and $4 p$ orbitals are used as valence orbitals for Sr. $2 s$ and $2 p$ orbitals are used for $\mathrm{O}$. The cutoff energy for the plane wave basis set is equal to $400 \mathrm{eV}$. In all cases, structures were fully relaxed with respect to volume as well as cell-internal and cell-external coordinates. Care was taken that for each structure a sufficient number of $\mathrm{k}$ points for the Brillouin-zone integration was chosen.

In a first step, we propose to study the structural stability of $\mathrm{SrTiO}_{3}$ compound by performing total energy calculations for the ideal perovskite-type crystal but also for two other structures of the isovalent $\mathrm{SrZrO}_{3}$ which are known to compete at room temperature [30,31].The first one is orthorhombic with the Pbnm space group while the other structure is pseudocubic on the basis of a doubled cubic perovskite cell with the $\mathrm{P} 2{ }_{1} 3$ space group. In 
Table I, we report the calculated structural parameters for all structures as well as the experimental data of the cubic perovskite structure.

As mentioned in [31], the distortions which occur in the pseudocubic structure are mainly due to rotation of the octahedral around the fourfold axes, which makes the parameter $\gamma$. the most important deviation. As this parameter is found to be equal to zero in our calculations, this structure can be considered as similar to the ideal perovskite structure. It will be no more discussed in the following. For the orthorhombic structure, the atomic coordinates in terms of the displacements $\mathrm{u}, \mathrm{v}$, and $\mathrm{w}$ from the special positions of the ideal cubic perovskite structure are given in Table I. The non-zero values of these parameters indicate local distortions which are consistent with octahedral tilting [30] although the tilt angles are smaller than in $\mathrm{SrZrO}_{3}$. The variation of the cohesive energy as a function of volume is shown in Fig. 1 for both ideal cubic and orthorhombic structures. The main result is that both structures display similar cohesive energies (a difference of less than $1 \mathrm{meV} / \mathrm{atom}$ ) at their equilibrium volumes. It is also observed that the orthorhombic structure is more stable than the cubic one at lower or higher volumes (higher or lower pressures). Our results obtained at lower volumes are in agreement with general rules for predicting phase transitions in perovskites due to octahedral tilting. Indeed, as mentioned in [32], if the octahedral are completely rigid (as we find at lower volumes), the only way in which the unit-cell volume can be reduced is by introducing tilts of the octahedral. It is mainly due to the fact that the $\mathrm{SrO}_{12}$ polyhedra are more compressible than the $\mathrm{TiO}_{6}$ octahedra. Therefore, the orthorhombic structure which displays a tilt system is more favourable than the cubic one to pressure effects. However, at higher volumes, the situation is quite different since our calculations display important deformations of the $\mathrm{TiO}_{6}$ octahedra with different values of $\mathrm{Ti}-\mathrm{O}$ bond lengths. In this case, general rules mentioned above cannot be applied and the behaviour of $\mathrm{SrTiO}_{3}$ as a function of pressure enters a new regime. We think that our results may serve as a new approach to explain phase transitions in epitaxial $\mathrm{SrTiO}_{3}$ films or by addition of impurities which favour octahedral distortions. Another possibility for a local distortion is an excess of Sr. It leads to the occurrence of the RP phases and it will be discussed in the next section in further details.

The calculated density of states (DOS) of $\mathrm{TiO}_{2}$ and $\mathrm{SrO}$ references as well as $\mathrm{SrTiO}_{3}$ in both cubic and orthorhombic structures are shown in Fig. $2 \mathrm{a}$ et $2 \mathrm{~b}$ respectively. The two DOS of $\mathrm{SrTiO}_{3}$ are very similar with only a slight shift of the valance band (VB) towards higher energies for the orthorhombic structure. The three peaks of the VB is made up predominately of the $\mathrm{O}-2 \mathrm{p}$ states with a minor admixture from $\mathrm{Ti} 3 \mathrm{~d}$ states in agreement with 


\section{III. $\mathrm{Sr}_{\mathrm{n}+1} \mathrm{Ti}_{\mathrm{n}} \mathrm{O}_{3 \mathrm{n}+1} \mathrm{COMPOUNDS:}$}

We first calculated the equilibrium structures of the $\mathrm{Sr}_{n+1} \mathrm{Ti}_{n} \mathrm{O}_{3 n+1}$ compounds for $\mathrm{n}=1$, 2 and 3. The initial structures were constructed computationally from experimental data and then fully relaxed with respect to volume, cell shape and internal structural parameters. In Table II, we report the calculated structural parameters for all structures as well as the experimental data. As for the perovskite structure, the agreement between the calculated and experimental parameters is very nice, the slight overestimation of the experimental data being a well-known feature of GGA treatment.

The formation energies of the Ruddlesden-Popper (RP) $\mathrm{Sr}_{n+1} \mathrm{Ti}_{n} \mathrm{O}_{3 n+1}$ phases were calculated according to the following reaction:

$$
\mathrm{SrO}+\mathrm{nSrTiO}_{3} \quad \rightarrow \quad \mathrm{Sr}_{\mathrm{n}+1} \mathrm{Ti}_{\mathrm{n}} \mathrm{O}_{3 \mathrm{n}+1}
$$

Our results are reported in Table III as well as results obtained in the previous theoretical studies. Our calculated formation energies are negative in agreement with the general trend obtained in previous results. However our results give much more negative formation energies (in excellent agreement with the experimental value of $\mathrm{Sr}_{2} \mathrm{TiO}_{4}$ [36]) and also they provide a different structural hierarchy. We find a lower formation energy for $\mathrm{Sr}_{3} \mathrm{Ti}_{2} \mathrm{O}_{7}$ than for $\mathrm{Sr}_{2} \mathrm{TiO}_{4}$, in agreement with empirical based results [21, 24] but in opposite to ab initio ones performed by Suzuki and Fujimoto [25]. Noguera [26] found values which are much smaller than ours. Moreover our results show lower formation energy for $\operatorname{Sr}_{4} \mathrm{Ti}_{3} \mathrm{O}_{10}$ even if the formation energy difference between $\mathrm{Sr}_{4} \mathrm{Ti}_{3} \mathrm{O}_{10}$ and $\mathrm{Sr}_{3} \mathrm{Ti}_{2} \mathrm{O}_{7}$ phases is smaller than that between $\mathrm{Sr}_{3} \mathrm{Ti}_{2} \mathrm{O}_{7}$ and $\mathrm{Sr}_{2} \mathrm{TiO}_{4}$. Let us mention that the formation energy of $\mathrm{Sr}_{4} \mathrm{Ti}_{3} \mathrm{O}_{10}$ 
obtained by Udayakumar and Cormack [21] remains constant (in fact all the structures for $\mathrm{n}$ $\geq 2$ display a constant formation energy) while the formation energy given by Mc Coy et al. [24] is smaller than that of $\mathrm{Sr}_{3} \mathrm{Ti}_{2} \mathrm{O}_{7}$. Quite surprisingly, Noguera [26] found a positive value for $\mathrm{Sr}_{4} \mathrm{Ti}_{3} \mathrm{O}_{10}$. Because of the energy differences of the competing structures are small we also have performed a set of calculations using the local density (LDA) approximation since a general source of inaccuracy might be due to the approximations for the exchange-correlation energy functional. Both sets of calculations give similar results, the largest difference being smaller than $5 \mathrm{meV}$. The DOS of the three RP phases are shown in Fig. 4(a-c). Their shapes are roughly similar to that of $\mathrm{SrTiO}_{3}$, the additional structures in both $\mathrm{VB}$ and $\mathrm{CB}$ being due mainly to two kinds of inequivalent oxygen and strontium atoms, those belonging to the $\mathrm{SrO}$ double layers and those from the $\mathrm{SrTiO}_{3}$ units.

Having negative formation energies is a necessary condition to study the feasibility of RP structures under thermodynamical equilibrium conditions but it is not a sufficient condition. Indeed since these phases correspond to different chemical compositions, one must also consider the reactions between them or in other terms to determine the ground states of the $\mathrm{SrO}_{-} \mathrm{SrTiO}_{3}$ section. First we find that the following reaction:

$$
\mathrm{SrTiO}_{3}+\mathrm{Sr}_{2} \mathrm{TiO}_{4} \quad \rightarrow \quad \mathrm{Sr}_{3} \mathrm{Ti}_{2} \mathrm{O}_{7}
$$

has an exothermic reaction energy of $-0.056 \mathrm{eV}$. Consequently, $\mathrm{Sr}_{3} \mathrm{Ti}_{2} \mathrm{O}_{7}$ is more stable than the associated combination of $\mathrm{Sr}_{2} \mathrm{TiO}_{4}$ and $\mathrm{SrTiO}_{3}$.

The second reaction of interest is:

$$
\mathrm{Sr}_{3} \mathrm{Ti}_{2} \mathrm{O}_{7}+\mathrm{SrTiO}_{3} \quad \rightarrow \quad \mathrm{Sr}_{4} \mathrm{Ti}_{3} \mathrm{O}_{10}
$$

which displays a much smaller reaction energy of $-0.016 \mathrm{eV}$. Such a result indicates that RP phases with $\mathrm{n}$ greater than 2 can be considered as metastable phases.

For compositions richer in $\mathrm{SrO}$ than $\mathrm{Sr}_{3} \mathrm{Ti}_{2} \mathrm{O}_{7}$, the following reaction is:

$$
\mathrm{SrO}+\mathrm{Sr}_{3} \mathrm{Ti}_{2} \mathrm{O}_{7} \quad \rightarrow \quad \mathrm{Sr}_{2} \mathrm{TiO}_{4}
$$

is energetically favourable $(-0.144 \mathrm{eV})$.

All our results suggest that equilibria in the $\mathrm{SrO}-\mathrm{SrTiO}_{3}$ system may be based on a series of three compounds, namely $\mathrm{Sr}_{2} \mathrm{TiO}_{4}, \mathrm{Sr}_{3} \mathrm{Ti}_{2} \mathrm{O}_{7}$ and $\mathrm{SrTiO}_{3}$. RP phases with $\mathrm{n}>2$ may form under special preparation conditions or if cation dopants were to be used. The inability to extract single phases of RP series for $n>2$ and the possible appearance of these phases as mixed ones confirms the experimental view. For instance the observation by Tilley [23] of the coherent intergrowth of lamellae of different widths of the various RP ( $n=3$ to 8 ) phases in a matrix of $\mathrm{Sr}_{3} \mathrm{Ti}_{2} \mathrm{O}_{7}$ can be explained by the absence of a thermodynamic driving force for ordering the RP structure layers. 


\section{SUMMARY AND CONCLUSIONS:}

$\mathrm{Ab}$ initio calculations were performed to shed light on the structural aspects of phase equilibria in the Strontium-Titanium-Oxygen System. For $\mathrm{SrTiO}_{3}$, the results of these calculations have revealed a strong competition between the perovskite structure and the orthorhombic one which is the first step to understand the occurrence of structural phase transitions in strained $\mathrm{SrTiO}_{3}$ films. Our calculations have also offered a theoretical basis for the Ruddlesden-Popper phases. We found that only the RP $\operatorname{Sr}_{n+1} \operatorname{Ti}_{n} \mathrm{O}_{3 n+1}$ phases with $n=1$ and 2 are ground states in the $\mathrm{SrO}_{-} \mathrm{SrTiO}_{3}$ system. We believe that the results presented in this paper illustrate the usefulness of first-principles based calculations in elucidating complex structural behaviour in non-stoichiometric compounds.

\section{AKNOWLEDGMENTS:}

We acknowledge Laboratoire de Physique et Modélisation des Milieux Condensés for computational resources on the PC cluster PHYNUM (CIMENT, Grenoble).

\section{REFERENCES:}

[1] M. Cardona, Phys. Rev. A 140, A651 (1965)

[2] V.E. Henrich , Rep. Prog. Phys. 48, 1481 (1985)

[3] J.G. Bednorz and K.A. Muller, Phys. Rev. Lett. 52, 2289 (1984)

[4] F. Gervais, B. Claes, and P. Odier, Mater. Res. Bull. 22, 1629 (1987)

[5] H.P.R. Frederikse, W.R. Thurber, and W.R. Hosler, Phys. Rev. A 134, A442 (1964)

[6] U. Balachandran and N.G. Error, J. Solid State Chem. 39, 351 (1981)

[7] U. Balachandran and N.G. Error, J. Electrochem. Soc. 129, 1021 (1982)

[8] B. Odekirk, U. Balachandran, N.G. Error, and J.S. Balkemore, Mater. Res. Bull. 17, 199 (1982)

[9] K.H. Kim, K.H. Yoon, and J.S. Choi, J. Phys. Chem. Solids 46, 1061 (1985)

[10] J.F. Schooley, W.R. Hosler, and M.L. Cohen, Phys. Rev. Lett. 12, 474 (1964) 
[11] J.F. Schooley, W.R. Hosler, E. Amber, J.H. Becker, M.L. Cohen, and C.S. Koonce, Phys. Rev. Lett. 14, 305 (1965)

[12] C.S. Koonce, M.L. Cohen, J.F. Schooley, W.R. Hosler, and E. R. Pfeiffer, Phys. Rev. 163, 380 (1967)

[13] M. Ziese, Rep. Prog. Phys. 65, 143 (2002)

[14] H. Dulli, E.W. Plummer, P.A. Dowben, J. Choi, and S.H. Liou, Appl. Phys. Lett. 77, 570 (2000)

[15] C.N. Borca, B. Xu, T. KOmesu, H-k Jeong, M.T.Liu, S.H. Liou, and P.A. Dowben, Surf. Sci. Lett. 512, L346 (2002)

[16] Y. Lu, X.W. Lee, G.O. Gong, G. Xiao, A. Gupta, P. Lecoeur, J.Z. Sun, Y.Y. Wang, and V.P. Dravid, Phys. Rev. B 54, R8357 (1996)

[17] T. Obata, T. Manako, Y. Shimakawa, and Y. Kubo, Appl. Phys. Lett. 74, 290 (1999)

[18] J.M. De Teresa, A. Barthelemy, A. Fert, J.P. Contour, F. MOntaigne, and P. Seneor, Science 286, 507 (1999)

[19] F. He, B.O. Wells, Z-G Ban, S.P. Alpay, S. Grenier, S.M. Shapiro, Weidong Si, A. Clark and X.X. Xi, Phys. Rev. B 70, 235405 (2004)

[20] S.N. Ruddlesden and P. Popper, Acta Crystallogr. 11, 54 (1958)

[21] K.R. Udayakumar and A.N. Cormack, J. Am. Ceram. Soc. 71, C-469 (1988)

[22] K.R. Udayakumar and A.N. Cormack, J. Phys. Chem. Solids 50, 55 (1989)

[23] R.J.D Tilley, J. Solid State Chem. 21, 293 (1977)

[24] M.A. McCoy, R.W. Grimes, and W.E. Lee, Philos. Mag. A 75, 833 (1997)

[25] T. Suzuki and M. Fujimoto, J. Of Appl. Phys. 89, 5622 (2001)

[26] C. Noguera, Phil. Mag. Lett. 80, 173 (2000)

[27] G. Kresse and J. Furthmüller, Comput. Mater. Sci. 6 (1996) 15; Phy. Rev. B 54 (1996) 11169;

[28] G. Kresse and D. Joubert, Phys. Rev. B 59 (1999) 1758

[29] J.P. Perdew and Y. Wang, Phy. Rev. B 45 (1992) 13244

[30] A. Ahtee, M. Ahtee, A.M. Glazer and A.W. Hewat, Acta. Cryst. B32, 3243 (1976)

[31] J.A.M. van Roosmalen, P. van Vlaanderen, and E.H.P. Cordfunke, J. Of Solid State

Chemistry 101, 59 (1992)

[32] R.J. Angel, J.Zhao and N.L. Ross, Phys. Rev. Lett. 95, 25503 (2005)

[33] G. Fabricius, E.L. Peltzer y Blanca, C.O.Rodriguez, A.P. Ayala, P. de la Presa, and A. Lopez Garcia, Phys. Rev. B 55, 164 (1997)

[34] S-Di Mo, W.Y. Ching, M.F. Chisholm and G. Duscher, Phys. Rev. B 60, 2416 (1999) 
[35] I. N. Yakovin and M.Gutowski, Phys. Rev. B 70, 165319 (2004)

[36] D.R. Lide, CRC Handbook of Chemistry and Physics $72^{\text {nd }}$ edition (Boston, Massachusetts: CRC Press) 
Figure Captions:

Figure 1: Calculated cohesive energy as a function of the volume for the perovskite and orthorhombic structures.

Figure 2: Total electronic DOS for: a) for $\mathrm{TiO}_{2}$ (full line); $\mathrm{SrO}$ (dotted line) b) $\mathrm{SrTiO}_{3}$ : full line, perovskite structure; dotted line orthorhombic structure.

Figure 3: Charge density difference $\rho_{\text {self }}(r)-\rho_{\text {at }}(r)$ between bulk and free atom in a) cubic and b) orthorhombic $\mathrm{SrTiO}_{3}$. Both compounds display a depletion of charge on $\mathrm{Ti}$ and $\mathrm{Sr}$ sites and a gain of charge on oxygen sites with respect to the electronic configuration of the atoms (the maximum is added under brackets in arbitrary units). The transfer of charge is drastically increased as the $\mathrm{TiO}_{6}$ octahedrons are tilted in the orthorhombic structure.

Figure 4: Total electronic DOS for: a) $\mathrm{Sr}_{2} \mathrm{TiO}_{4}$; b) $\mathrm{Sr}_{3} \mathrm{Ti}_{2} \mathrm{O}_{7}$; c) $\mathrm{Sr}_{4} \mathrm{Ti}_{3} \mathrm{O}_{10}$ 


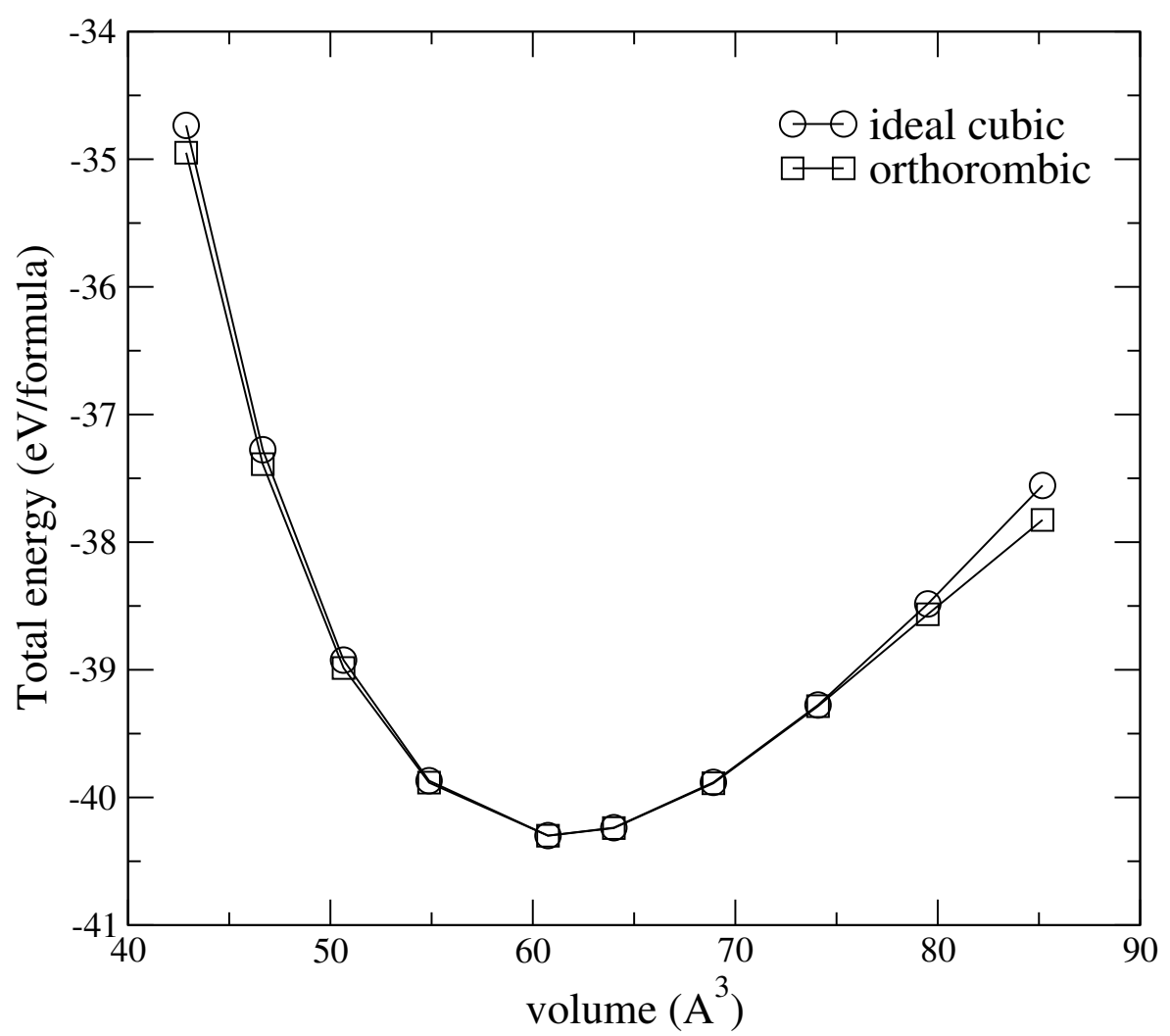

33 


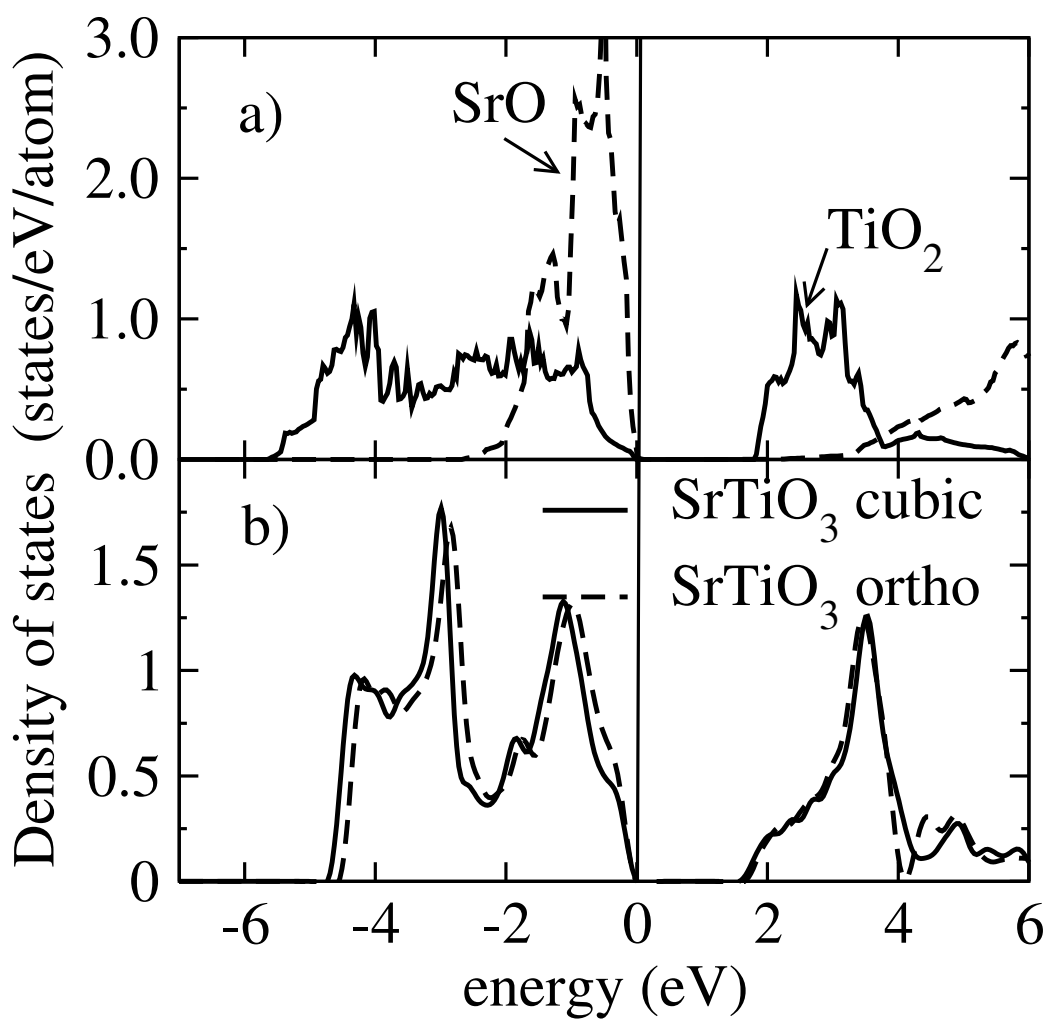


Figure 3:
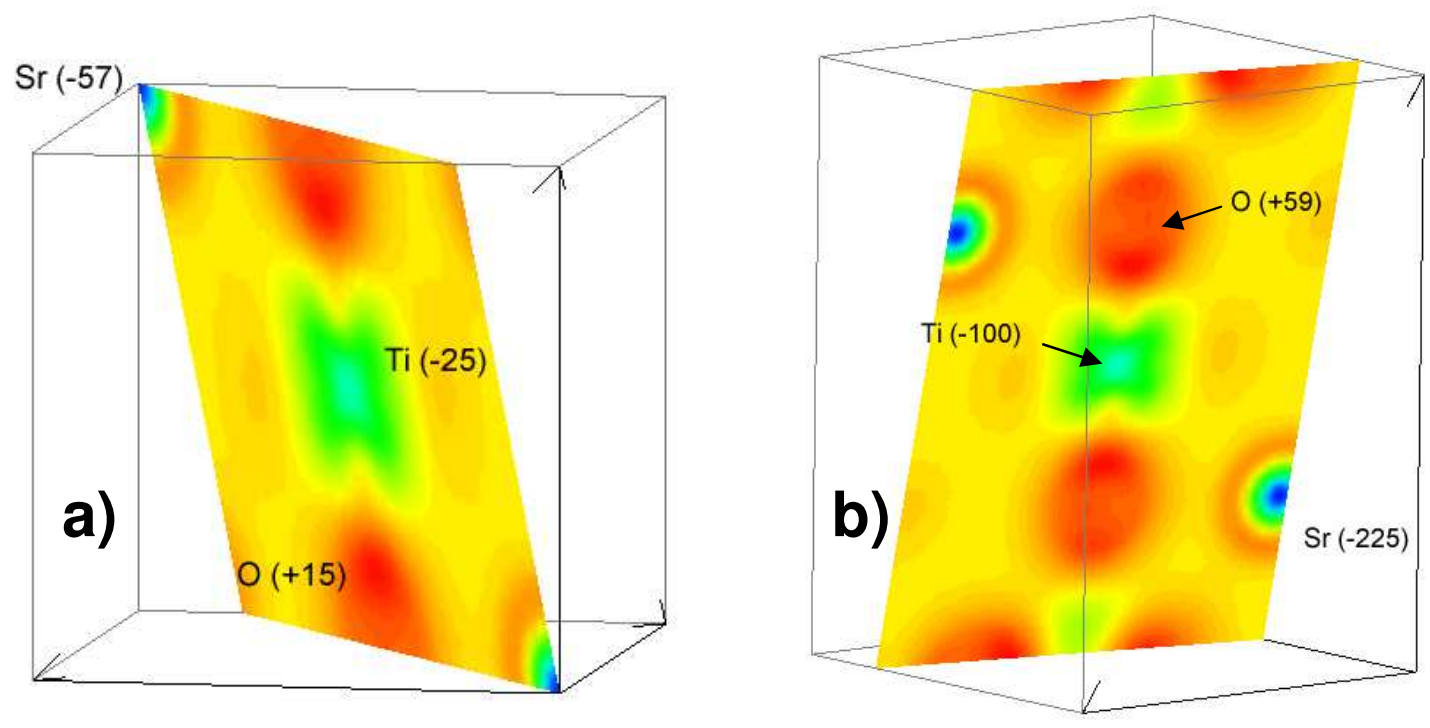


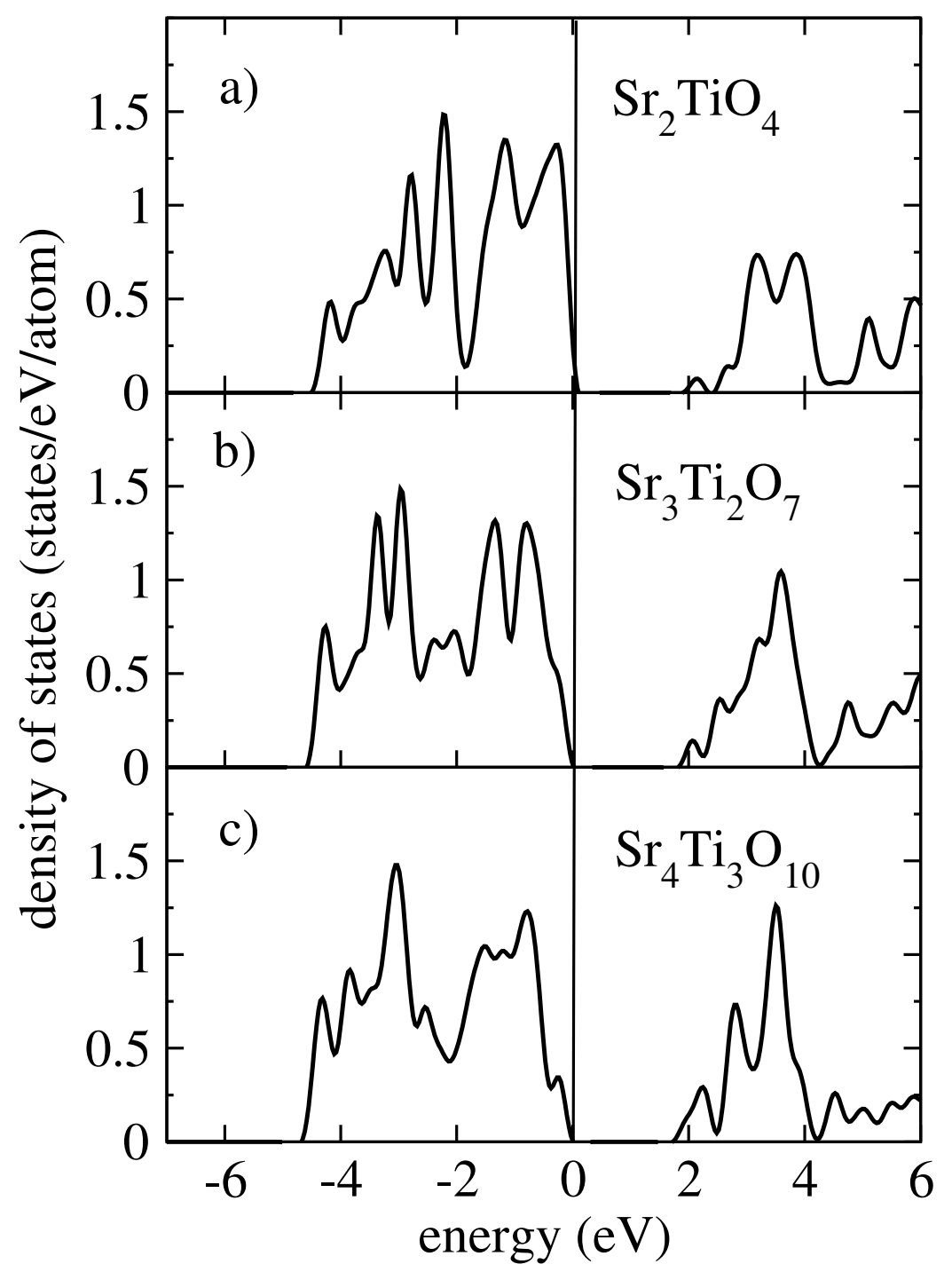


Table I: Space group and calculated lattice parameters (in $\AA$ ), oxygen positions (in direct coordinates) and crystallographic structures of $\mathrm{SrTiO}_{3}$ (experimental and prototypes), compared to experimental values [under brackets]. u, v, w indicate possible displacements from the ideal cubic perovskite positions according to space group Pbnm. Oxygen atoms are small red balls, Ti are grey balls embedded in the octahedrons of oxygen and $\mathrm{Sr}$ are the blue balls.

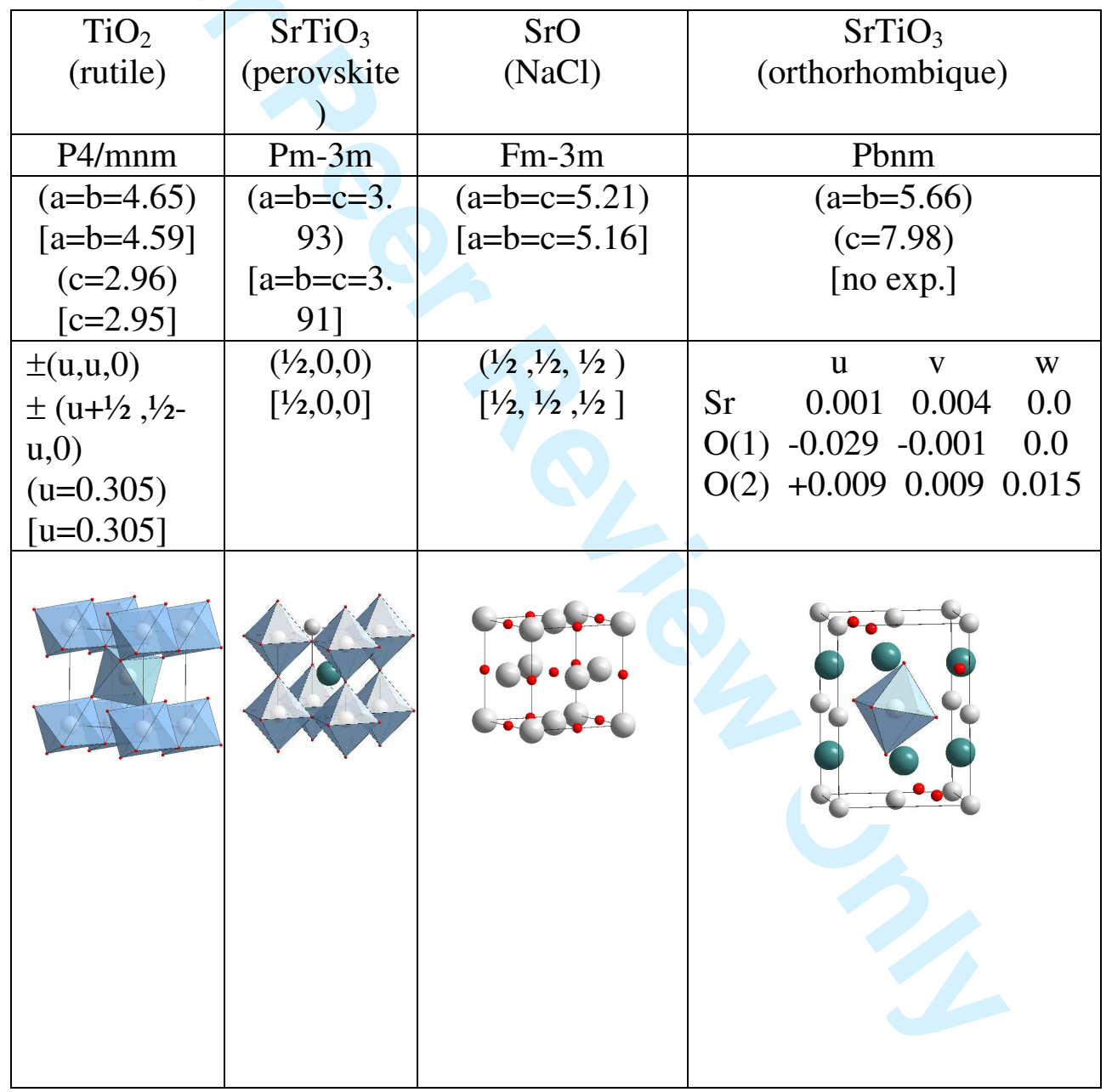


Table II: Space group and calculated lattice parameters (in $\AA$ ), oxygen positions (in direct coordinates) and crystallographic structures of the $\mathrm{RP} \mathrm{Sr}_{\mathrm{n}+1} \mathrm{Ti}_{\mathrm{n}} \mathrm{O}_{3 \mathrm{n}+1}$ phases with $\mathrm{n}=1,2$ and 3 (under parenthesis), compared to experimental values [under bracket, Ref. 20]. The defect structures can be formed from $\mathrm{SrTiO}_{3}$ by removing a (001) sheet of $\mathrm{TiO}_{6}$ octahedra and shearing the layer above by $1 / 2[111]$. Oxygen atoms are small red balls, Ti atoms are grey balls embedded in the octahedrons of oxygen and $\mathrm{Sr}$ are the blue balls.

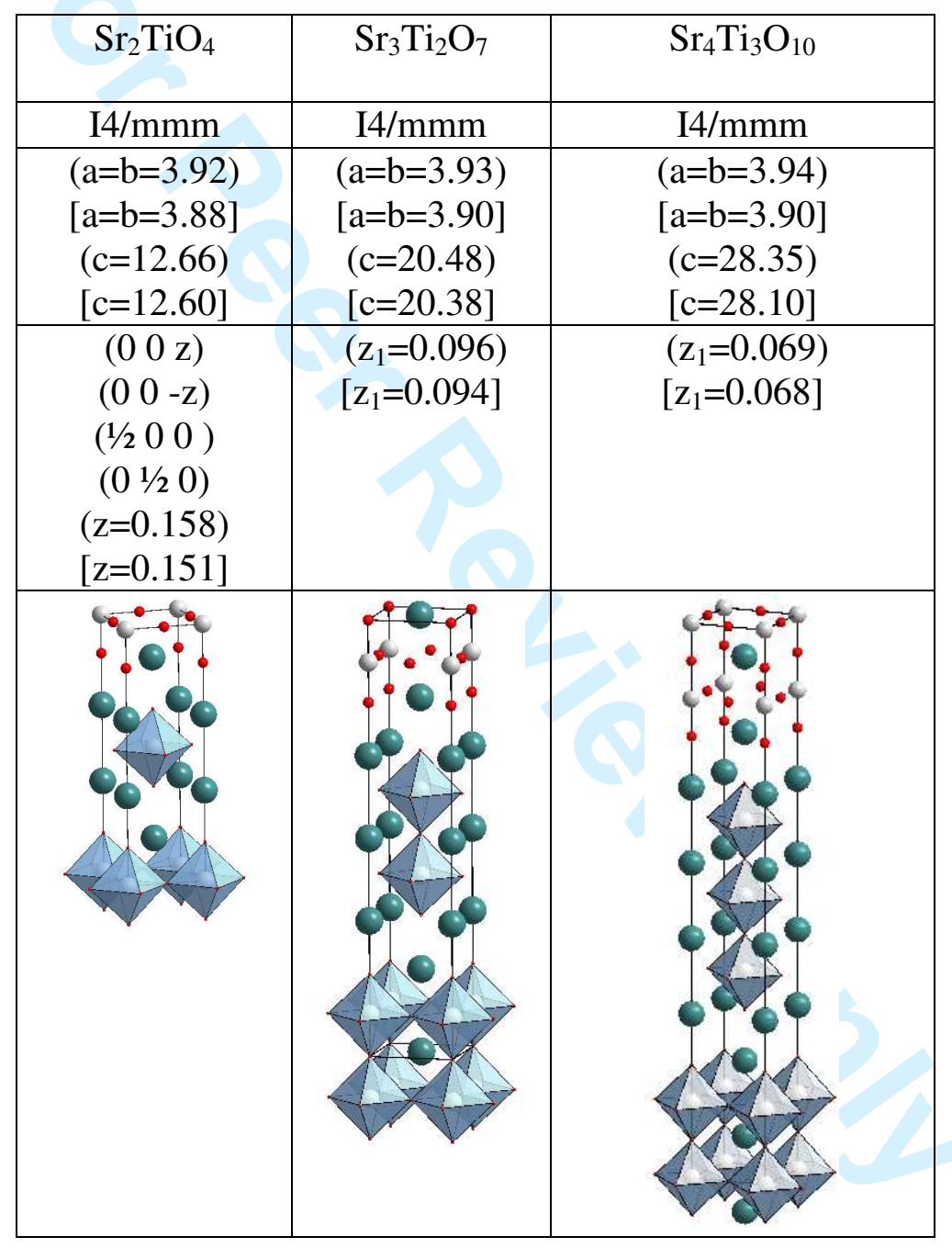


Table III: Cohesive energies (Ec) of the $\mathrm{RP} \mathrm{Sr}_{\mathrm{n}+1} \mathrm{Ti}_{\mathrm{n}} \mathrm{O}_{3 \mathrm{n}+1}$ phases with $\mathrm{n}=1,2$ and 3 and their formation energies (Ef) from: $\mathrm{SrO}_{+} \mathrm{nrTiO}_{3} \rightarrow \mathrm{Sr}_{\mathrm{n}+1} \mathrm{Ti}_{\mathrm{n}} \mathrm{O}_{3 \mathrm{n}+1}$

\begin{tabular}{|c|c|c|c|c|c|c|c|}
\hline \multicolumn{2}{|c|}{ Ec (eV/atom } & \multicolumn{6}{|c|}{ Ef $\quad(e V)$} \\
\hline & & Present work & Ref. [36] & Ref.[21] & Ref. [24] & Ref.[25] & Ref.[26] \\
\hline $\mathrm{SrO}$ & 6.097 & & & & & & \\
\hline $\mathrm{SrTiO}_{3}$ & 8.059 & & & & & & \\
\hline $\mathrm{Sr}_{2} \mathrm{TiO}_{4}$ & 7.527 & -0.200 & -0.24 & -0.11 & -0.15 & -0.158 & -0.04 \\
\hline $\mathrm{Sr}_{3} \mathrm{Ti}_{2} \mathrm{O}_{7}$ & 7.753 & -0.252 & & -0.14 & -0.21 & -0.144 & -0.10 \\
\hline $\mathrm{Sr}_{4} \mathrm{Ti}_{3} \mathrm{O}_{10}$ & 7.844 & -0.269 & 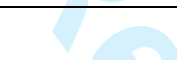 & -0.14 & -0.19 & & +0.02 \\
\hline
\end{tabular}

